\title{
A Study of the Sea Breeze by the Numerical Experiment
}

\author{
by \\ M. Magata \\ Meteorological Research Institute, Tokyo
}

(Received June 9, 1965)

\begin{abstract}
The effect of the general current with vertical shear and the release of latent heat by condensation on the development of the sea breeze circulation is studied by the numerical experiment. In order to find out the reasonable distribution of the diffusion coefficient which decides the vertical transfer of heat and plays an important role in such an experiment, the calculated temperature distributions by the equation of diffusion are compared with the observation in the case of an inversion layer due to nocturnal radiation. A condition of heat balance at the earth's surface is given by taking into account insolation, nocturnal radiation, conduction and eddy transfer of heat.
\end{abstract}

\section{Introduction}

The linear theory of the sea and land breeze has been developed by many authors for a long time. Several authors have recently used the method of numerical integration of the non-linear equations of motion for the theoretical study of the sea breeze (PeArce (1955), Fisher (1961), Estoque (1961, 1962)).

This phenomenon is regarded as an atmospheric circulation resulting from the heat transfer processes between the ground and the atmosphere by small-scale eddies. The mechanism of vertical heat transfer depends directly on the existing temperature and velocity. EsTOQUe (1961) first introduced such mechanism of heat transfer in his theoretical investigation of the sea breeze. The author tried to decide the vertical distribution of diffusion coefficient by comparing the calculated temperature distribution using the equation of diffusion, with the observed one in a typical case of inversion layer due to nocturnal radiation, and used this distribution of diffusion coefficient in the numerical experiment of the sea breeze. No one has in such an experiment considered the condition of heat balance at the earth's surface, but the author introduced this condition by taking into account the insolation, radiation, conduction and eddy transfer of heat.

ESTOQUE (1962) studied the effects of the uniform general current without vertical shęar on the development of the sea breeze circulation. In this paper the effects of the general current with vertical shear are investigated and it is shown that the development of circulation depends on the direction of vertical shear. Finally the release of latent heat by condensation is shown to be an important factor near the sea breeze front. The author introduced the effect of the release of latent heat as 
a reversible condensation process. But the mechanisms of generation of cloud and rainfall have not been clearified, and so the variation of heat transfer due to these effects can not be known through the numerical experiment.

\section{Basic equations}

The sea breeze over a straight shoreline will be investigated using a rectangular co-ordinate system whose $x$-axis is normal to the shoreline and $z$-axis is along the vertical. The vertical cross-section of the atmosphere to be considered is bounded at the bottom by the earth's surface and at the top by the level, $Z=H$. The lateral boundaries are located at $x=0$ and $x=D$.

Instead of using the pressure $p$, it is convenient to use the non-dimensional variable $\pi$,

$$
\pi=\left(\frac{p}{P}\right)^{\kappa},
$$

where $P$ is a reference pressure and $\kappa$ is the ratio $R / c_{p}=\left(c_{p}-c_{v}\right) / c_{p} . \quad T, \rho$ and $\theta=T(P / p)^{\kappa}$ are temperature, density and potential temperature respectively. If $T_{c}$, $p_{c}$ and $\pi_{c}$ are assumed to be quantities in an adiabatically stratified atmosphere, then

$$
\begin{aligned}
& T_{c}=\text { const. }-\frac{g}{c_{p}} z, \\
& \pi_{c}=\text { const. }-\frac{g}{c_{i^{\prime}} \Theta} z,
\end{aligned}
$$

where $\Theta=T_{c}\left(P / p_{c}\right)^{\kappa}$ is a uniform potential temperature.

If the potential temperature $\theta$ is assumed to be almost constant $\Theta$, the pressure gradient force can be expressed as follows:

$$
\begin{aligned}
& \frac{1}{\rho} \frac{\partial p}{\partial x}=c_{p} \theta \frac{\partial \pi}{\partial x}=c_{p} \theta \frac{\partial \pi^{\prime}}{\partial x} \fallingdotseq c_{p} \Theta \frac{\partial \pi^{\prime}}{\partial x}, \\
& \frac{1}{\rho} \frac{\partial p}{\partial z}=c_{p} \theta \frac{\partial \pi}{\partial z}=c_{p} \theta \frac{\partial \pi^{\prime}}{\partial z}-g \frac{\theta}{\Theta} \doteqdot c_{p} \Theta \frac{\partial \pi^{\prime}}{\partial z}-g \frac{\theta^{\prime}}{\Theta}-g,
\end{aligned}
$$

where $\pi^{\prime}=\pi-\pi_{c}$ and $\theta^{\prime}=\theta-\theta$. Therefore the equations of motion, continuity and thermodynamics in the incompressible atmosphere where the potential temperature is almost constant, may be written as follows:

$$
\begin{aligned}
& \frac{\partial u}{\partial t}+u \frac{\partial u}{\partial x}+u \frac{\partial u}{\partial z}-f v=-c_{p} \Theta \frac{\partial \pi^{\prime}}{\partial x}+\frac{\partial}{\partial z}\left(K \frac{\partial u}{\partial z}\right), \\
& \frac{\partial v}{\partial t}+u \frac{\partial v}{\partial x}+u \frac{\partial v}{\partial z}+f u=-c_{p} \Theta \frac{\partial \pi^{\prime}}{\partial y}+\frac{\partial}{\partial z}\left(K \frac{\partial v}{\partial z}\right), \\
& \frac{\partial u}{\partial t}+u \frac{\partial w}{\partial x}+w \frac{\partial u}{\partial z}=-c_{p} \Theta \frac{\partial \pi^{\prime}}{\partial z}+g \frac{\theta^{\prime}}{\Theta}, \\
& \frac{\partial u}{\partial x}+\frac{\partial w}{\partial z}=0, \\
& \frac{\partial \theta^{\prime}}{\partial t}+u \frac{\partial \theta^{\prime}}{\partial x}+u \frac{\partial \theta^{\prime}}{\partial z}=H_{\theta}+\frac{\partial}{\partial z}\left(K \frac{\partial \theta^{\prime}}{\partial z}\right),
\end{aligned}
$$


In this paper, instead of (8) the following hydrostatic equation will be assumed:

$$
c_{p} \Theta \frac{\partial \pi^{\prime}}{\partial z}-g \frac{\theta^{\prime}}{\Theta}=0
$$

The second terms in the right-hand sides of (6), (7) and (10) express eddy diffusion, and the first term in the right-hand side of (10) represents the release of latent heat by condensation and evaporation.

According to Ogura and Phillips (1962), the system of equations (6)-(10) is suitable to describe the motion where the potential temperature is almost constant, and does not include the high-frequency acoustic waves. Furthermore, in the shallow convection $\theta^{\prime}$ may be regarded to represent the deviation from the adiabatically stratified temperature.

Now, the specific humidity $q_{v}$ and the liquid water $q_{w}$ are assumed to be governed by the following equations :

$$
\begin{aligned}
& \frac{\partial q_{v}}{\partial t}+u \frac{\partial q_{v}}{\partial x}+w \frac{\partial q_{v}}{\partial z}=\frac{\partial}{\partial z}\left(K \frac{\partial q_{v}}{\partial z}\right)+C_{q}, \\
& \frac{\partial q_{w}}{\partial t}+u \frac{\partial q_{w}}{\partial x}+u \frac{\partial q_{w}}{\partial z}=\frac{\partial}{\partial z}\left(K \frac{\partial q_{w}}{\partial z}\right)-C_{q},
\end{aligned}
$$

where $C_{q}$ means the variation of $q_{v}$ and $q_{w}$ by condensation and evaporation. And sea temperature $T_{1}$ and land temperature $T_{2}$ which depends on the depth $z$ (directed downward from the earth's surface) only, are assumed to be dominated by the equations of diffusion as follows:

$$
\begin{aligned}
& \frac{\partial T_{1}}{\partial t}=K_{1} \frac{\partial^{2} T_{1}}{\partial z^{2}} \\
& \frac{\partial T_{2}}{\partial t}=K_{2} \frac{\partial^{2} T_{2}}{\partial z^{2}}
\end{aligned}
$$

where $K_{1}$ is the diffusion coefficient of sea and $K_{2}$ is the coefficient of heat conduction of land.

$C_{q}$ and $H_{\theta}$ are estimated every time step of the numerical integration. In Fig. 1, e and $T$ are vapour pressure and temperature respectively and $P_{0}$ represents a state where an adjustment of condensation or evaporation is not taken into account in a time step. If the curve (2) shows the Clausius-Claperon equation for the saturation vapour pressure which is formulated by

$$
\frac{d e}{d T}=\frac{0.622 L e}{R T^{2}},
$$

$P_{0}$ is in the state of supersaturation. Therefore adjustment is necessary to bring $P_{0}$ to the curve

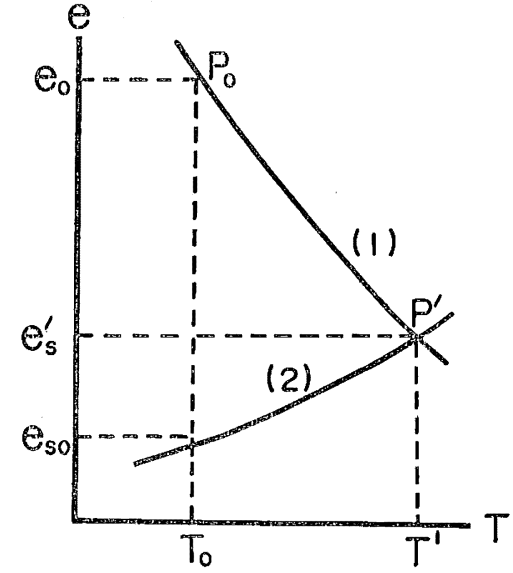

Fig. 1. Graphical interpretation of the saturation-adjustment in the numerical integration. 
(2). According to Mcdonald (1963), the following method will be used. If $L$ is the latent heat of vaporization, the heating $d T$ accompanying a small amount of adiabatic-isobaric condensation is given by

$$
-\frac{0.622 L}{p} d e=c_{p} d T
$$

which specifies the curve (1) in Fig. 1. An intersecting point $P^{\prime}$ of the two curves (1) and (2) represents the final saturated state. The difference forms of (16) and (17) are written as follows:

$$
\begin{aligned}
& \left(e_{s}^{\prime}-e_{s 0}\right) /\left(T^{\prime}-T_{0}\right)=\left(0.622 L e_{s 0}\right) / R T_{0}{ }^{2}, \\
& e_{0}-e_{s}^{\prime}=\left(c_{p} p / 0.622 L\right)\left(T^{\prime}-T_{0}\right) .
\end{aligned}
$$

On the other hand, the saturation vapour pressure is given on the water by

$$
e_{s 0}=6.11 \exp \left\{\frac{17.27\left(T_{0}-273\right)}{T_{0}-35.7}\right\} \text {. }
$$

From (18), (19) and (20), $e_{s}^{\prime}$ and $T^{\prime}$ can be calculated for the given $e_{0}$ and $T_{0}$. In the case of subsaturation the same adjustment is carried out, so long as there is liquid water necessary for evaporation.

\section{Boundary conditions and numerical integration procedure}

As a continuity equation, the following form is used instead of (9):

$$
\frac{\partial^{2} w}{\partial z^{2}}=-\frac{\partial^{2} u}{\partial x \partial z} \text {. }
$$

The conditions of heat balance at the earth's surface are given as follows at sea surface $z=0$ and $0 \leq x \leq D$ :

$$
\begin{aligned}
& \theta^{\prime}=T_{1}, \\
& S-h\left(T_{1}-C_{h}\right)-c_{1} \rho_{1} K_{1} \frac{\partial T_{1}}{\partial z}+c_{p} \rho K \frac{\partial \theta^{\prime}}{\partial z}=0, \\
& q_{v}=\alpha_{1} q_{s},
\end{aligned}
$$

at land surface $z=0$ and $D_{1} \leq x \leq D$ :

$$
\begin{aligned}
& \theta^{\prime}=T_{2}, \\
& S-h\left(T_{2}-C_{h}\right)-c_{2} \rho_{2} K_{2} \frac{\partial T_{2}}{\partial z}+c_{p} \rho K \frac{\partial \theta^{\prime}}{\partial z}=0, \\
& q_{v}=\alpha_{2} q_{s},
\end{aligned}
$$

where the first terms of (23) and (26) represent insolation, the second terms longwave radiation where $h$ is a cooling coefficient and $C_{h}$ is the specific temperature at which there is neither cooling nor heating, the third terms heat transfer downward and the fourth terms eddy transfer of heat (LöNNQVIST, 1962). The insolation $S$ is given as a function of time such as Table $1 . q_{s}$ is saturated specific humidity and $\alpha_{1}$ and $\alpha_{2}$ are constants : $0 \leqq \alpha_{1}, \alpha_{2} \leqq 1$. 
Table 1. Values of insolation function.

\begin{tabular}{c|c|c|c|c|c|c|c|c|c|c|c|c}
\hline Time (hr.) & $\begin{array}{c}18 \sim 24 \\
0 \sim 6\end{array}$ & 7 & 8 & 9 & 10 & 11 & 12 & 13 & 14 & 15 & 16 & 17 \\
\hline $\begin{array}{c}\text { Insolation } \\
\text { (cal/m } \text { m }^{2} \text { min.) }\end{array}$ & 0 & 1000 & 3200 & 5600 & 7600 & 8700 & 9000 & 8700 & 7600 & 5600 & 3200 & 1000 \\
\hline
\end{tabular}

The remaining boundary conditions are as follows:

$$
\begin{aligned}
& (u)_{z=0}=(v)_{z=0}=0, \quad\left(\frac{\partial u}{\partial z}\right)_{z=H}=\left(\frac{\partial v}{\partial z}\right)_{z=H}=0, \\
& \left(\frac{\partial u}{\partial x}\right)_{x=0}=\left(\frac{\partial u}{\partial x}\right)_{x=D}=0, \quad\left(\frac{\partial v}{\partial x}\right)_{x=0}=\left(\frac{\partial v}{\partial x}\right)_{x=D}=0, \\
& (w)_{z=0}=(w)_{z=H}=0, \\
& \left(\frac{\partial \theta^{\prime}}{\partial x}\right)_{x=0}=\left(\frac{\partial \theta^{\prime}}{\partial x}\right)_{x=D}=0, \quad\left(\frac{\partial \theta^{\prime}}{\partial z}\right)_{z=H}=0, \\
& \left(\frac{\partial q_{v}}{\partial x}\right)_{x=0, D}=0, \quad\left(\frac{\partial q_{w}}{\partial x}\right)_{x=0, D}=0, \quad\left(\frac{\partial q_{v}}{\partial z}\right)_{z=H}=0, \quad\left(\frac{\partial q_{w}}{\partial z}\right)_{z=0, H}=0 .
\end{aligned}
$$

In the numerical calculation, $D=195 \mathrm{~km}, D_{1}=90 \mathrm{~km}$ and $H=1500 \mathrm{~m}$ are used, and $\Delta x=15 \mathrm{~km}, \Delta z=100 \mathrm{~m}$ for the atmosphere and $\Delta z=0.1 \mathrm{~m}$ for the ground are assumed. Forward time extrapolations were used, assuming a time increment $\Delta t$ of $10 \mathrm{~min}$. This choice of $J$ t was simply estimated so that

$$
\Delta t<\frac{\Delta x}{u}, \quad \Delta t<\frac{(\Delta z)^{2}}{2 K},
$$

were satisfied simultaneously for the smallest $\Delta x$ and for estimated maximum values of $u$ and $K$. Vertical velocity and pressure are estimated from the diagnostic equations (21) and (11) respectively, while the other elements are decided by the prognostic equations.

\section{Inversion layer and diffusion coefficient}

In this paper, the effect of the boundary layer near the ground are not taken into account, and the adequate coefficient of diffusion is estimated by comparing the numerical solutions of diffusion equation with the observed one in a process of generation of the inversion layer. The diffusion equations of soil temperature $T_{g}$ $(z<0)$ and air temperature $T(Z>0)$ are written as follows:

$$
\begin{array}{ll}
\frac{\partial T}{\partial t}=\frac{\partial}{\partial z}\left(K \frac{\partial T}{\partial z}\right), & (z>0) \\
\frac{\partial T_{g}}{\partial t}=K_{g} \frac{\partial^{2} T_{g}}{\partial z^{2}}, & (z<0)
\end{array}
$$

where $K$ is a function of $z$ only and $K_{g}$ is assumed to be constant. The boundary conditions are

$$
\begin{aligned}
& (T)_{z=0}=\left(T_{g}\right)_{z=0}, \\
& \left(S-h\left(T_{g}-C_{h}\right)-c_{g} \rho_{g} K_{g} \frac{\partial T_{g}}{\partial z}+c_{p} \rho K \frac{\partial T}{\partial z}\right)_{z=0}=0,
\end{aligned}
$$


which are the same as (22) and (23).

It is first assumed that $K$ is a constant. Then the analytical solutions of (33) and (34) under the boundary conditions (35) and (36) can be obtained. If the insolation function $S$ is assumed to be expanded into a Fourier series of time $t$ such as

$$
S=b_{0}+\sum_{l=1}^{n}\left(b_{l} \cos l \omega t+c_{l} \sin l \omega t\right),
$$

then the required analytical solution may be written as follows:

$$
\begin{gathered}
T=\frac{b_{0}+h C_{h}}{h}-\sum_{l=1}^{n} \frac{\exp \left(-\sqrt{\frac{l \omega}{2 K}} z\right)}{\sqrt{\left(\alpha_{l}+h\right)^{2}+\alpha_{l}^{2}}}\left\{b_{l} \cos \left(l \omega t+\sqrt{\frac{l \omega}{2 K}} z-\delta_{l}\right)\right. \\
\left.+c_{l} \sin \left(l \omega t+\sqrt{\frac{l \omega}{2 K}} z-\delta_{l}\right)\right\}, \quad(z \geqslant 0) \\
T_{g}=\frac{b_{0}+h C_{l}}{h}-\sum_{l=1}^{n} \frac{\exp \left(\sqrt{\frac{l \omega}{2 K_{g}}} z\right)}{\sqrt{\left(\alpha_{l}+h\right)^{2}+\alpha_{l}^{2}}}\left\{b_{l} \cos \left(l \omega t+\sqrt{\frac{l \omega}{2 K_{g}}} z-\delta_{l}\right)\right. \\
\left.+c_{l} \sin \left(l \omega t+\sqrt{\frac{l \omega}{2 K_{g}}} z-\delta_{l}\right)\right\}, \quad(z \leqslant 0)
\end{gathered}
$$

where

$$
\left\{\begin{array}{l}
\tan \delta_{l}=\frac{\alpha}{\alpha+h} \\
\alpha_{l}=c_{p} \rho \sqrt{\frac{K l \bar{\omega}}{2}}+c_{g} \rho_{g} \sqrt{\frac{K_{g} l \omega}{2}} .
\end{array}\right.
$$

From the above solution, the amplitude of diurnal variation and the height of inversion layer can be estimated. If the insolation $S$ is given as Table 1 , the Fourier coefficients $b_{l}, c_{l}$ may be obtained as follows (LöNNQVIST, 1962):

$$
\begin{array}{llll}
b_{0}=2880 & & & \\
b_{1}=3980 & b_{2}=880 & b_{3}=270 & b_{4}=-50 \\
c_{1}=-120 & c_{2}=20 & c_{3}=100 & c_{4}=-20 . \quad\left(\mathrm{cal} / \mathrm{m}^{2} \mathrm{~min}\right)
\end{array}
$$

Thus the main features of the diurnal variation may be estimated from the first terms of the Fourier series of (38) and (39). If $2 Z_{c}$ is defined by the height where the amplitude of the first term of the Fourier series of (38) becomes smaller than $0.5^{\circ} \mathrm{C}, Z_{c}$ may be considered to represent the height of the inversion layer. The calculated values of the amplitudes of diurnal variation at the surface and the heights of inversion layer $Z_{c}$ are given in Table 2.

When $K$ is not a constant, the analytical solution can not be obtained. Therefore the numerical solutions of (33) and (34) under the boundary conditions (35) and (36) will be studied for the various vertical distribution of $K$, comparing with the observed diurnal variation. 
Table 2. Theoretical diurnal variation of temperature.

\begin{tabular}{l|c|c|c|c|c|c}
\hline & & & \multicolumn{2}{|c|}{$K=10^{5} \mathrm{~cm}^{2} / \mathrm{sec}($ Air $)$} & \multicolumn{2}{|c}{$K=10^{4} \mathrm{~cm}^{2} / \mathrm{sec}($ Air $)$} \\
\hline & $\begin{array}{c}\rho c \\
\left(\mathrm{cal} / \mathrm{cm}^{3}{ }^{\circ} \mathrm{C}\right)\end{array}$ & $K\left(\mathrm{~cm}^{2} / \mathrm{sec}\right)$ & Amp. $\left({ }^{\circ} \mathrm{C}\right)$ & $Z_{c}(\mathrm{~m})$ & Amp. $\left({ }^{\circ} \mathrm{C}\right)$ & $Z_{c}(\mathrm{~m})$ \\
\hline Snow & 0.22 & 0.003 & 7.1 & 715 & 17.3 & 293 \\
Soil & 0.57 & 0.005 & 5.6 & 634 & 10.6 & 253 \\
Ocean (1) & 1.00 & 50.00 & 0.1 & 0 & 0.1 & 0 \\
Ocean (2) & 1.00 & 0.10 & 1.9 & 347 & 2.2 & 123 \\
Water & 1.00 & 0.0015 & 5.7 & 639 & 11.5 & 218 \\
\hline
\end{tabular}

Fig. 2 (a) shows an example of the diurnal variation of the vertical distribution of air temperature observed at the Kawaguti tower on 26-27 November 1952 (TosHA, 1953). In this case, the height of the well-developed inversion layer is about $150 \mathrm{~m}$ and the vertical gradient of temperature near the ground is distinguished. In the numerical computation, the various elements of the boundary condition (36) are assumed as follows. The insolation $S$ at an arbitrary time is given by the interpolated value of Table $1 . h$ and $C_{h}$ of the nocturnal radiation term $h\left(T_{g}-C_{h}\right)$ are assumed to be $0.002 \mathrm{cal} / \mathrm{cm}^{2} \mathrm{~min}$. and $-60^{\circ} \mathrm{C}$ respectively, according to LöNNQVIST (1962). The remaining constants are given as follows; $c_{g} \rho_{g}=0.57 \mathrm{cal} / \mathrm{cm}^{3}{ }^{\circ} \mathrm{C}, K_{g}=$ $0.005 \mathrm{~cm}^{2} / \mathrm{sec}$ for a soil and $c_{p} \rho=3 \times 10^{-4} \mathrm{cal} / \mathrm{cm}^{3}{ }^{\circ} \mathrm{C}$ for an air. $\Delta z=50 \mathrm{~m}$ (in (33)), $\Delta z=0.1 \mathrm{~m}$ (in (34)) are used as special gride size and $\Delta t=1.5 \mathrm{~min}$. as time step. As the initial conditions (at 0 o'clock), the surface temperature $T_{0}$ and the adiabatic lapse rate are given, and the soil temperature is assumed to be equal to the surface temperature everywhere. Fig. 2 (b) is a case of $T_{0}=0^{\circ} \mathrm{C}$ and $K=10^{4} \mathrm{~cm}^{2} / \mathrm{sec}$, and Fig. 2 (c) is a case of $T_{0}=0^{\circ} \mathrm{C}$ and $K=10^{5} \mathrm{~cm}^{2} / \mathrm{sec}$. In Fig. 2 (d) and Fig. 2 (e), $T_{0}=5^{\circ} \mathrm{C}$, and $(K)_{z=0}$ is $1 / 6 \times 10^{4} \mathrm{~cm}^{2} / \mathrm{sec}$ and $1 / 6 \times 10^{5} \mathrm{~cm}^{2} / \mathrm{sec}$ respectively. In both cases, it is assumed that $K$ increases linearly with height and above $200 \mathrm{~m}$ takes the constant values $10^{4} \mathrm{~cm}^{2} / \mathrm{sec}$ and $10^{5} \mathrm{~cm}^{2} / \mathrm{sec}$ respectively. In these figures, the straight lines represent the adiabatic lapse rate. As may be seen by comparing Fig. 2 (c) and Fig. 2 (e) with the observed case Fig. 2 (a), the constant diffusion coefficient $K$ is improper in our problem. And it seems that the case of Fig. 2 (d) is the best of these four cases, though this case does not sufficiently explain the observed one. In the following numerical experiments of the sea breeze, this diffusion coefficient $K$ will be used. But it is, of course, desirable that $K$ should be decided according to the distributions of wind and temperature from hour to hour. Such studies on the diffusion coefficient have been done by many researchers but no formulation which is effective for such numerical experiment has been found.

\section{Results of numerical experiments on the sea breeze}

This paragraph is devoted to an account of the results of numerical integration of a system of equations (6), (7), (10), (11), (12), (13), (14), (15) and (21) under the boundary conditions (22)-(32), using the diffusion coefficient $K$ mentioned in the last paragraph. As the insolation, half the values in Table 1 are used, and the initial time is fitted to 6 o'clock. $K_{1}=0.1 \mathrm{~cm}^{2} / \mathrm{sec}, K_{2}=0.005 \mathrm{~cm}^{2} / \mathrm{sec}, c_{1} \rho_{1}=1 \mathrm{cal} / \mathrm{cm}^{3}{ }^{\circ} \mathrm{C}$ and $c_{2} \rho_{2}=0.57 \mathrm{cal} / \mathrm{cm}^{3}{ }^{\circ} \mathrm{C}$ are assumed in (14), (15), (23) and (26). Fig. 3, (a), (b) 
and (c) are the distributions of wind and temperature at $t=1,5$ and $9 \mathrm{hr}$. respectively in a case where the initial state of an atmosphere is assumed to be adiabatically stratified and motionless. As a temperature, deviation from the adiabatically stratified temperature is shown. At $t=1$ and $3 \mathrm{hr}$. there is a weak land breeze generated by the nocturnal cooling of land. At $t=9 \mathrm{hr}$. the sea breeze is predominant accompanied by an ascending current at about $30 \mathrm{~km}$ from the shore, and warm air is carried upwards. The sea breeze circulation is most predominant at this time. It is remarkable that another weak circulation appears at $50-90 \mathrm{~km}$ from the shore. This has been pointed out by Estoque (1962). Fig. 4 is a conditionally unstable case where the initial temperature lapse rate is about $0.73{ }^{\circ} \mathrm{C} / 100 \mathrm{~m}$, the initial relative humidity $100 \%$ and the air is assumed to be always saturated at the land surface. Of course, the air is saturated with water-vapor on the sea and not saturated on the land in many actual cases. In order to clarify the effect of condensation, it was assumed that the air was saturated on the land. In this figure, temperature is shown by the deviation from the initial value. The other conditions are the same as in Fig. 3. The sea breeze circulation in this case is a little stronger than the one in Fig. 3. The distribution of temperature at $t=9 \mathrm{hr}$. is especially remarkable by the influence of the release of latent heat. Fig. 5 shows the distribution of condensed liquid water at $t=9 \mathrm{hr}$. As may be seen from this figure, there is much liquid water in the ascending current and in the upper layer. It is due to the artificial condition $(\partial T / \partial z)_{z=H}=0$ at the upper boundary and the initial condition that there is much liquid water in the upper layer. Fig. 6 represents the distribution of the submarine and underground temperature, and Fig. 7 is the distribution of pressure at the same time.

Next, the effects of the general current on the sea breeze circulation are studied, neglecting the release of latent heat by the condensation and evaporation. It is assumed that the initial temperature stratification is adiabatic and that the initial general current is in a geostrophic balance. The effect of the uniform general currents have been studied by EsToQUE (1962). Fig. 10 shows the vertical distributions of general currents which are used in the numerical experiments. $\omega_{M}$ is the maximum vertical velocity in the sea breeze circulation at $t=9 \mathrm{hr}$. Fig. 8 (a), (b) and (c) are the distributions of wind and temperature in the case of the general current of Fig. 10 (a), at $t=1,5$ and $9 \mathrm{hr}$. respectively, and Fig. 9 is a case of Fig. 10 (b). As may be inferred from these figures, the strength of the sea breeze circulation depends on the vertical wind shear as well as on the wind velocity.

\section{Summary}

The characteristic methods and results of the numerical experiment on the sea breeze that have not so far been obtained are as follows;

i) The diffusion coefficient was conveniently decided by comparing the calculated temperature with the observation of the inversion layer.

ii) The boundary conditions at sea and land surface were given by the heat balance relations. 


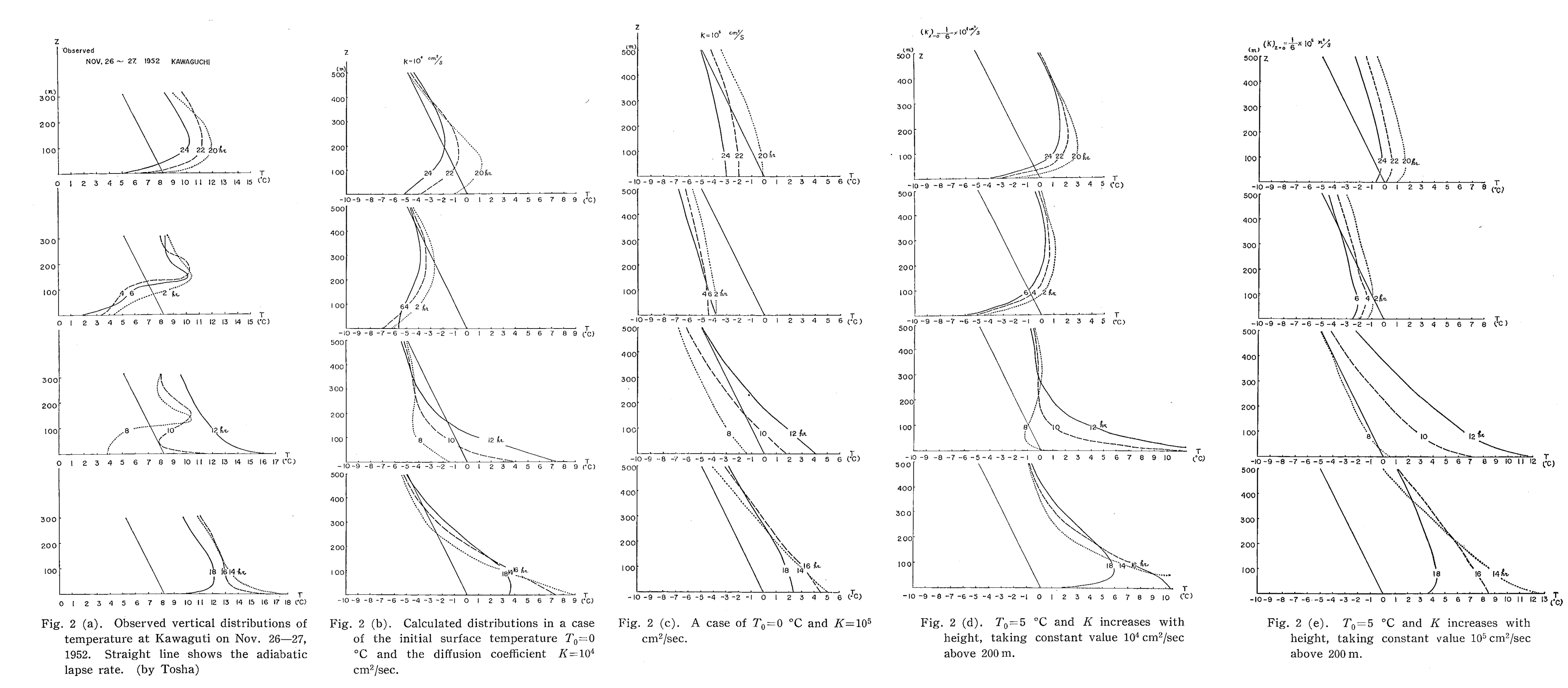




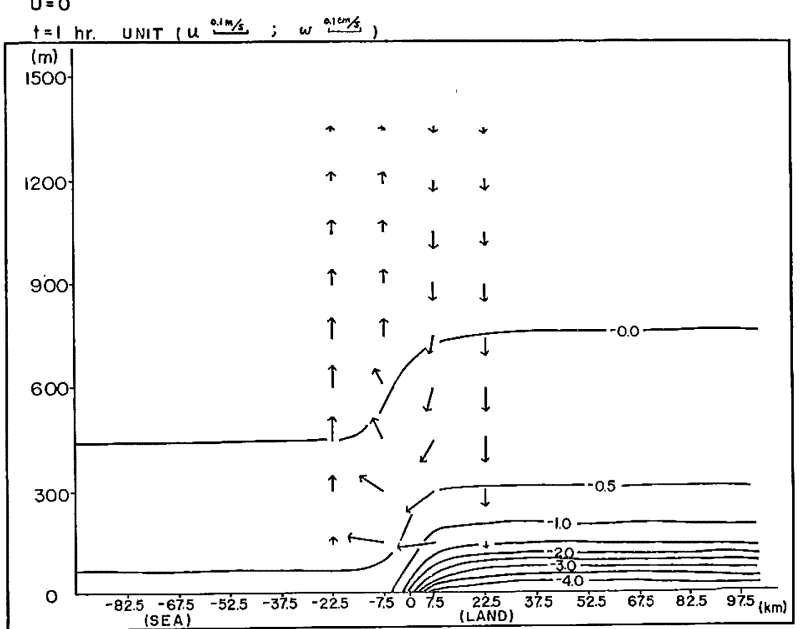

(a)

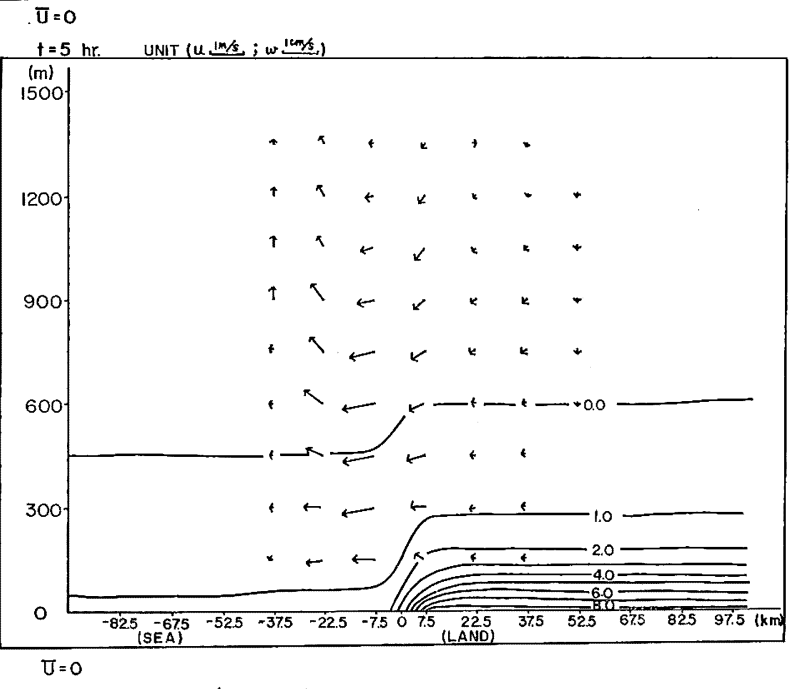

(b)

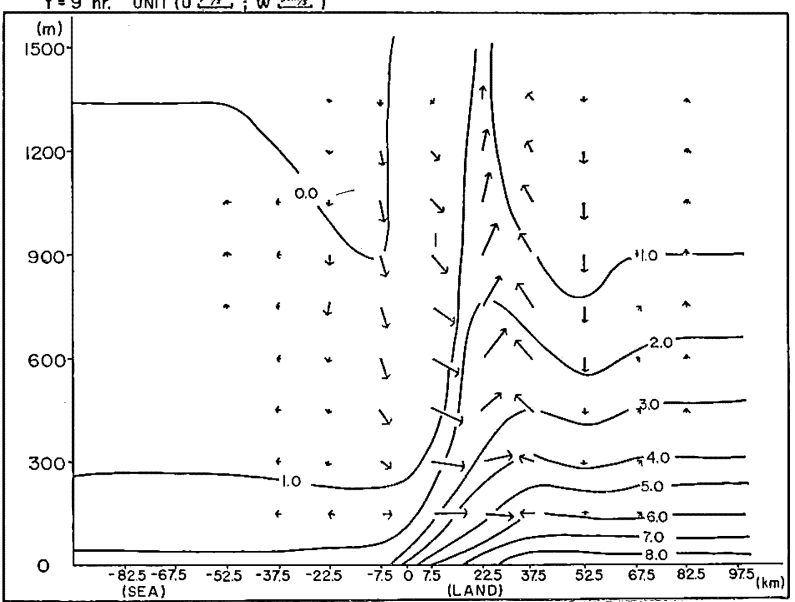

(c)

Fig. 3. Calculated distributions of wind and temperature. Initial general current $U=0$, and effect of condensation is neglected. Abscissa is distance from shoreline and ordinate is height. (a) is a case at $t=1 \mathrm{hr}$., (b) $t=5$ hr. and (c) $t=9 \mathrm{hr}$. 
$\bar{U}=0$

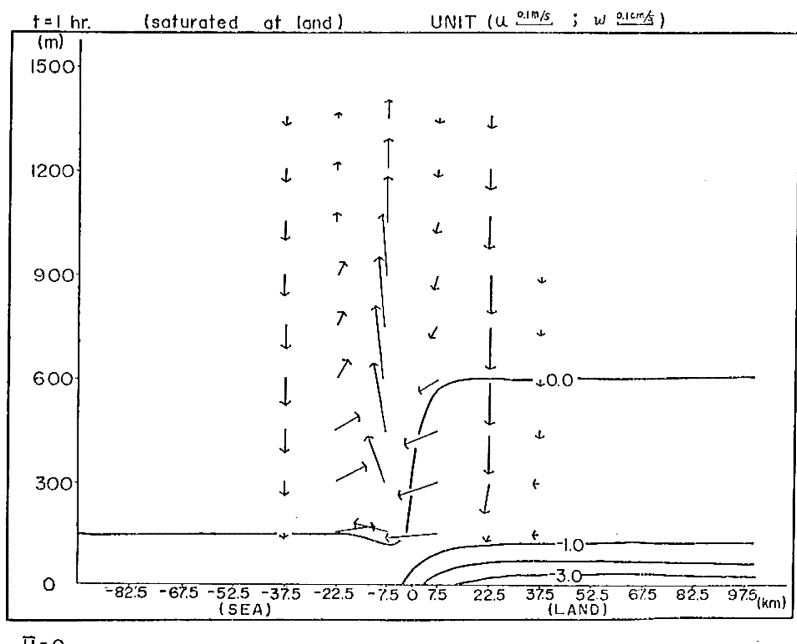

$\overline{\mathrm{U}}=0$

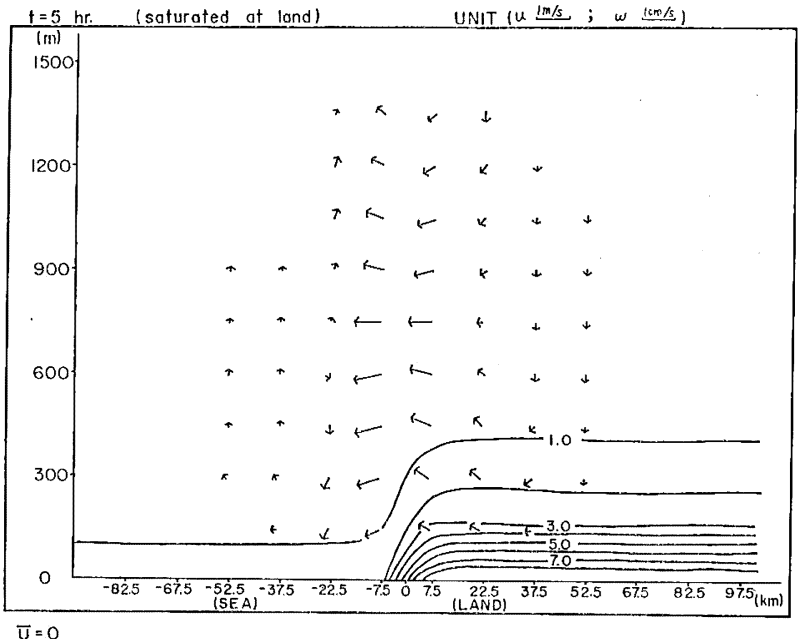

$t=9 \mathrm{hr}$. (saturated at land)

$t=9$
$(m)$

1500

(a)

$$
\text { ) }
$$
UNIT (u $5 \mathrm{mss} ; \omega .5 \mathrm{cms})$

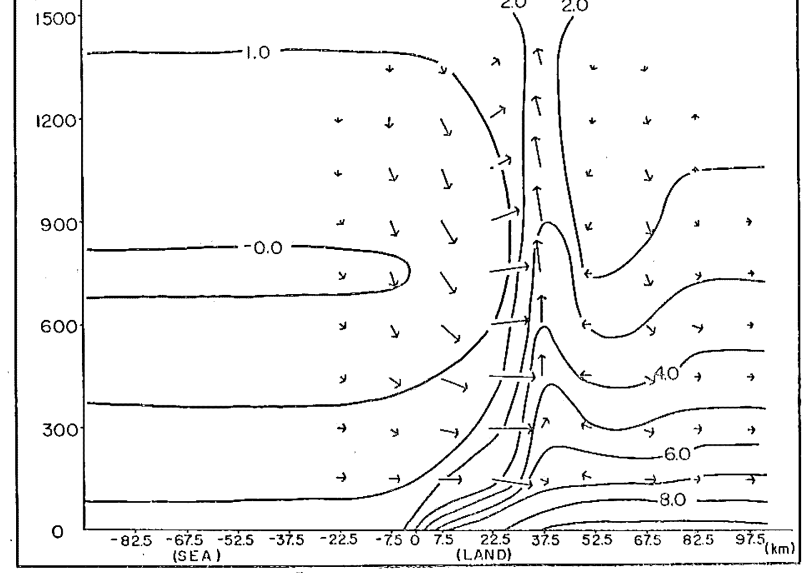

(a)

(b)

(c)

Fig. 4. Same as Fig. 3, but for $U=0$, and conditionally unstable case. 
$\uparrow=9 \mathrm{hr} . \quad \bar{U}=0$

LIQUID WATER (saturated at land)

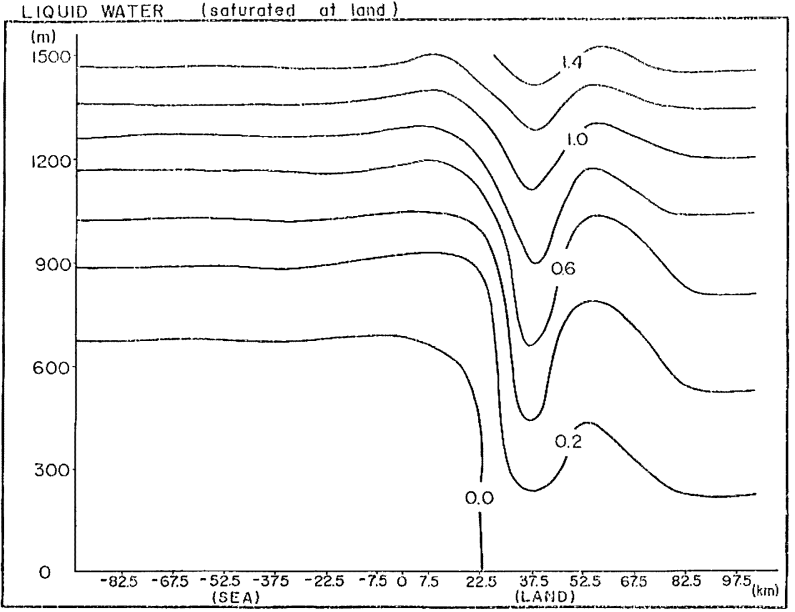

$t=9 \mathrm{hr} . \quad \mathrm{J}=0$

SEA ANO LAND TEMPERATURE (soturated at land)

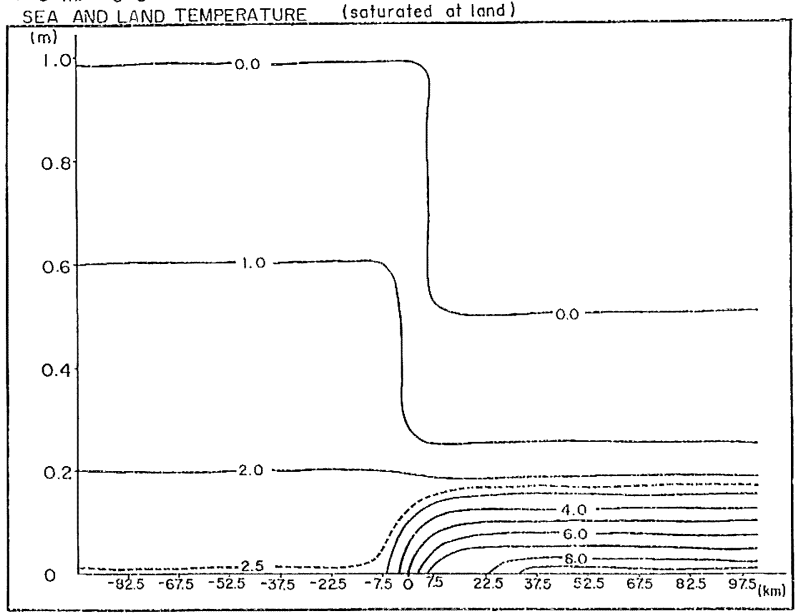

$t=9 \mathrm{hr} . \bar{U}=0$

PRESSURE (sclurated of lond)

$(\mathrm{mb})$

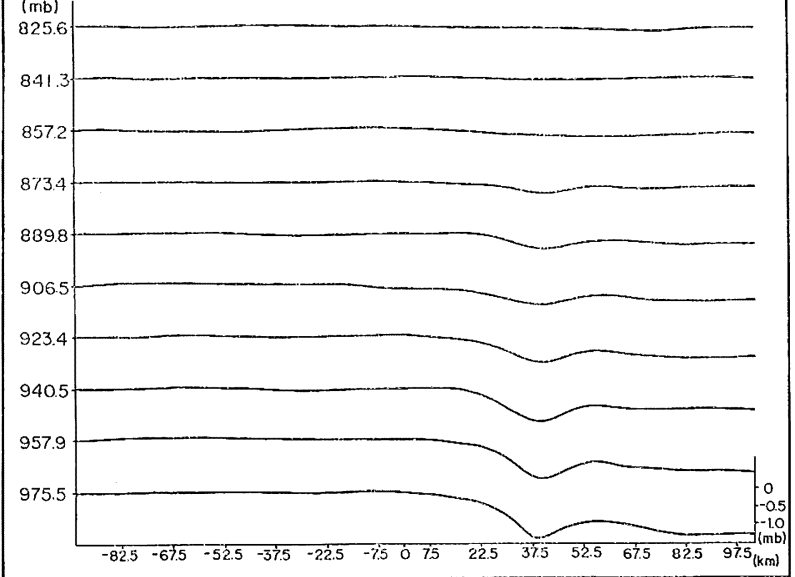

Fig. 5. Distribution of liquid water content in a case of Fig. 4 (c).
Fig. 6. Distribution of submarine and underground temperature in a case of Fig. 4 (c).
Fig. 7. Distribution of pressure in a case of Fig. 4 (c). 

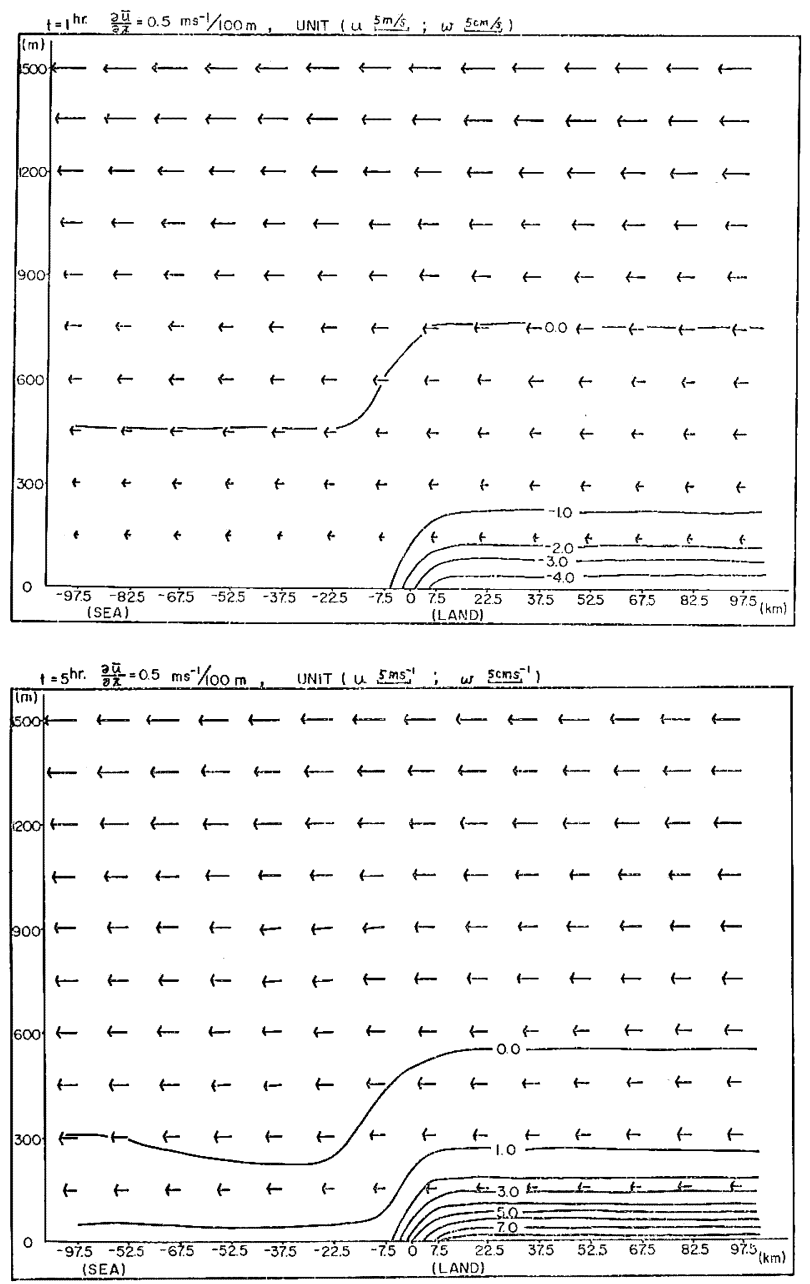

(b)

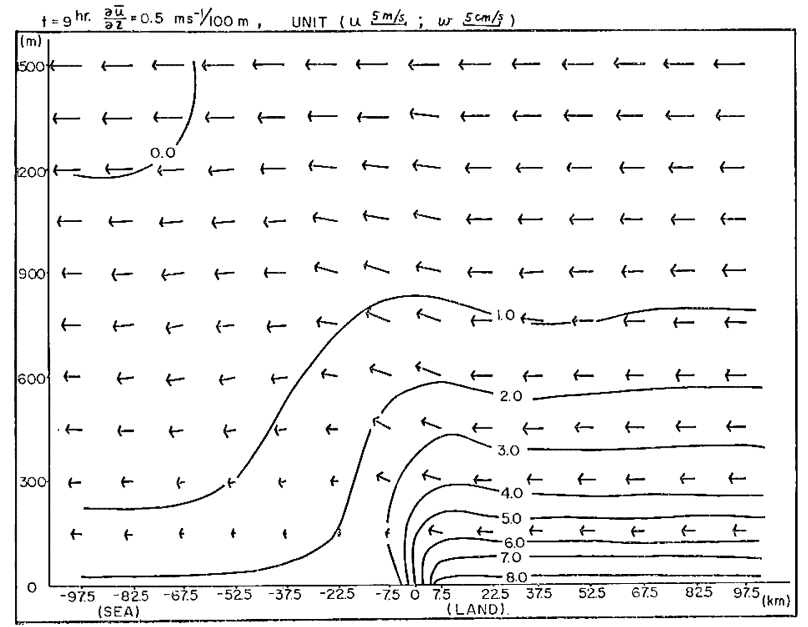

(c)

Fig. 8. Same as Fig. 3, but for $\partial U / \partial z=0.5(\mathrm{~m} / \mathrm{s}) / 100 \mathrm{~m}$, neglecting condensation. 
$\overline{\mathrm{U}}=\mathrm{L}$. L.J.

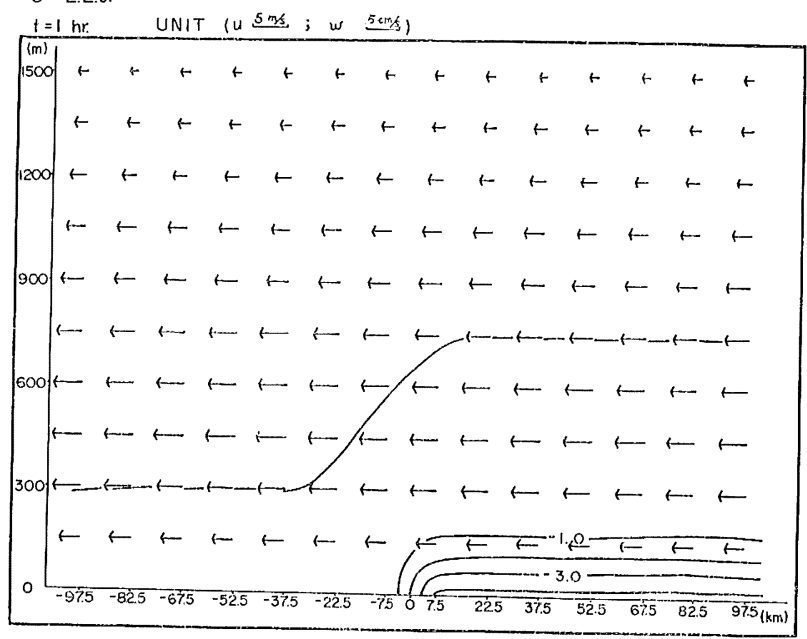

(a)

$\bar{U}=$ L.L.J.

$\mathrm{t}=5 \mathrm{hr} \quad$ UNIT $(\mathrm{u} 5 \mathrm{~m} / \mathrm{s}$. ; w $5 \mathrm{~cm} / \mathrm{s})$

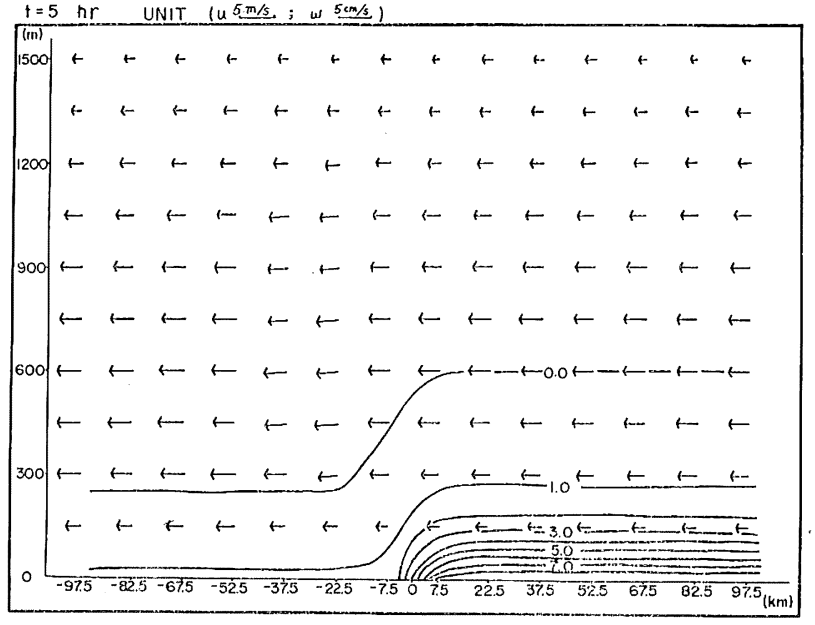

(b)

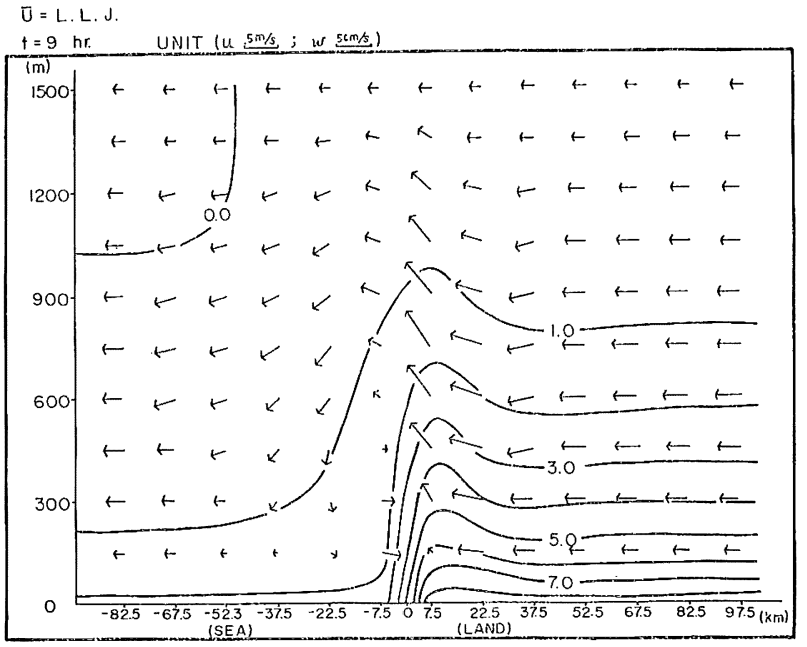

(c)

Fig. 9. Same as Fig. 8, but for general current corresponding to Fig. 10 (b). 

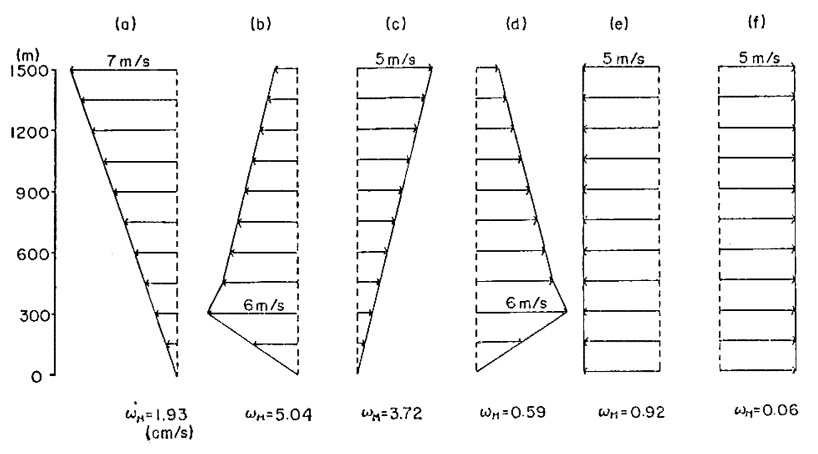

Fig. 10. Initial general currents used in calculations and maximum vertical velocities $\left.{ }^{(}\right)_{M}$ appeared at $t=9 \mathrm{hr}$.

iii) The effects of the release of latent heat by the condensation and evaporation were studied.

iv) It was shown that the vertical shear as well as the velocity of the general current was an effective factor in the development of the sea breeze circulation.

Acknowledgments-The author wishes to express his hearty thanks to Dr. K. TAKAHASH for his kind encouragement throughout this study. He also wishes to express his hearty thanks to the staff members of his laboratory for their kind discussions with him and to Misses K. Nishida and Y. Ozaki for their valuable assistance.

\section{References}

Estoque, M. A., 1961: A theoretical investigation of the sea breeze. Quart. J. R. Meteor. Soc., $87,134-146$.

Estoque, M. A., 1962: The sea breeze as a function of the prevailing synoptic situation. J. Meteor., 19, 244-250.

Frsher, E. L., 1961: A theoretical study of the sea breeze. J. Meteor., 18, 216-233.

LöNNQvist, O., 1962: On the diurnal variation of surface temperature. Tellus, 14, 96-101.

Mcdonald, J. E., 1963: The saturation adjustment in munerical modelling of fog. J. Meteor., 20, 476-478.

Ogura, Y., and N. A. Phrulips, 1962: Scale analysis of deep and shallow convection in the atmosphere. J. Meteor., 19, 173-179.

Pearce, R. P., 1955: The calculation of a sea-breeze circulation in terms of the differential heating across the coastline. Quart. J. R. Meteor. Soc., 81, 351-381.

Tosha, M., 1953: Temperature inversion in the lower atmosphere. Journ. Meteor. Res. 5, 649654, (in Japanese). 


\title{
数値実験による海陸風の研究
}

\author{
曲田光夫
}

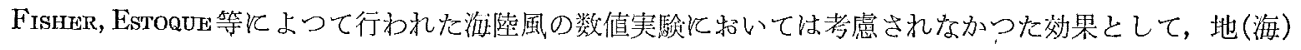
表面飞和ける熱平衡，㠜結とよる潜熱，一般流の垂直歪等の効果を主題として䛅算を実施した。地(海)表

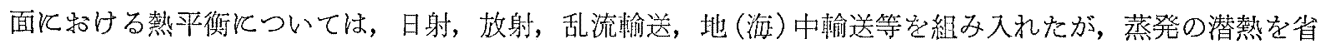
略した。実際には雲に上る日射，放射の変動が重要であるが，この効果もここでは考虑できなかつた。凝 結熱は現象を活発化させ, 一般流の歪の効果は, 丕の正負が問題飞なるようである。従来の安定度理諭で は, 歪の自乗の形できいてくるので, この点てついては更に研独を進めなければならない。また, 乱流拡 散係数飞ついては, 接地近転層が形成された場合の父温の実測值を, 抾散方程式を解いて求めた值と試行 実験的飞比较して決めた。出来れば，拡散係数を風と気温の分布の函数として時々刻々飞計算して行くの が望ましいが，この点燸ついて今のところうまく行かなかつた。 